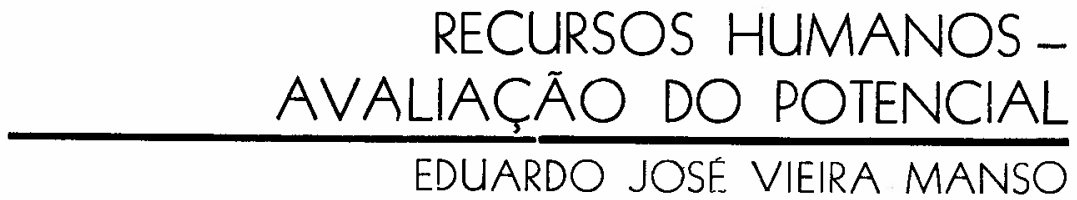

"Quem julga com a vontade nunca pode julgar bem, $A$ razão é muito clara: quem julga com entendimento se entende mal, julga mal; se entende bem, julga bem. Porém, quem juiğa com a vontade, cu queira mal, ou queira bem, sempre julga mal: se quer mal, julgá como apaixonado; se quer bem, julga como cego." - PE. ANTONIO VIEIRA

Neste breve ensaio pretendemos sugerir a adoção, pelo departamento do pessoal ou de relações industriais, de um currículo relativo à vida dos empregados, que abranja não só os dados antecedentes à sua admissão, mas também os fatos marcantes de sua passagem pela emprêsa até à data em que se extinguir a relação empregatícia ou, excecionalmente, até ao têrmo das eventuais conseqüências da rescisão contratual. Seu pressuposto essencial é o de que a emprêsa tenha, como filosofia, em primeiro lugar, a valorização do elemento humano e, em segundo, o seu mais eficiente aproveitameito possível.

Se as diretrizes de administração do pessoal forem estabelecidas de modo a justificar investimentos destinados ao bem-estar dos empregados, e se a emprêsa tiver interêsse na integração dos trabalhadores no corpo social da comunidade de trabalho, ser-lhe-á óbvia a conveniêucia de adotar o método que ora nos propomos a apresentar. Entre-

Eduardo José Vieira Manso - Gerente do Departamento do Pezsoal da C5BEC S/A. Engenharia e Indústria. 
tanto, mesmo que a emprêsa seja orientada exclusivamente no sentido do lucro, ainda assim será defensável a adoção do método em questão, principalmente se atinarmos que ao administrador cabe administrar, antes de tudo, pessoas.

Nosso escopo é oferecer uma sugestão para evitar o desperdício dos recursos humanos, uma vez que tanta ênfase vem sendo dada ao melhor aproveitamento dos recursos materiais. Não se trata de nenhuma descoberta sensacional, mas simplesmente da sistematização, planejada com objetivos concretos e definidos, de normas e operações rotineiras, de cuja prática, embora habitual, poucos conhecem as finalidades. Como é pelo estudo do passado que se pode prever o futuro, e porque a obtenção de dados a pasteriori está sujeita a distorções, preconizamos êste método pelo qual o registro dos fatos pode ser efetuado simultâneamente à sua ocorrência ou, pelo menos, imediatamente depois.

\section{O CONHECIMENTO DAS PESSOAS}

Como se pode verificar pelo conjunto de fichas sugeridas (vide o Anexo), os dados referentes aos testes de inteligência, às provas de conhecimentos, aos testes de personalidade e às observações feitas por ocasião da entrevista devem ser pormenorizadamente registrados, não para abarrotar arquivos mortos, mas para que o empregador possa, a qualquer momento, compará-los com as atitudes efetivamente reveladas pelo trabalhador durante todo o período em que perdure a relação empregatícia. As fases de treinamento, os progressos observados, os conflitos surgidos, as eventuais penalidades disciplinares, promoções, remoções, modificações salariais, férias, licenças, tudo, enfim, há de ser objeto de cuidadosa anotação, te forma a permitir, quando convier, rápida e fácil consulta.

Assim como é pelo estudo dos fatos passados que se escreve a História, a história de cada pessoa sòmente pode ser bem compreendida pela análise e interpretação de seu 
comportamento anteriormente manifesto. Faz-se mister, pois, conhecer as pessoas para melhor aproveitá-las, confiando-lhes tarefas coerentes com sua capacidade, inclinação natural, habilitação profissional e, até certo ponto, com seus próprios interêsses pessoais.

O êxito da aplicação de uma política de pessoal que se oriente no sentido de não frustrar as pessoas, mas que explore, no bom sentido, os aspectos positivos dos conflitos, não confundindo a solução de tais conflitos com sua eliminação pura e simples, está diretamente condicionado ao conhecimento das pessoas. A emprêsa que sustente entre seus objetivos o de manter um clima no qual as pessoas possam realizar-se integralmente, satisfazendo, inclusive, suas necessidades de ordem cultural, há de estar altamente preparada para o desenvolvimento de programas dessa natureza.

O ideal seria que a emprêsa não se empenhasse apenas no sentido de procurar conhecer seus colaboradores o menos superficialmente possível; mas que envidasse seus melhores esforços no intuito de fazer-se conhecer por êstes e pelos candidatos ao seu quadro de pessoal, oferecendo-lhes, de antemão, um retrospecto vivo de sua história, a imagem real de sua atuação.

Por outro lado, deveria constituir preocupação dos candidatos o estudo de cada emprêsa, para que na celebração do contrato individual de trabalho houvesse, realmente, acôrdo sinalagmático de vontades e não sòmente mera adesão por parte do empregaldo às cláusulas contratuais e aos regulamentos da emprêsa, êstes muitas vêzes ignorados, quando não inexistentes. Se, o instituto jurídico e social do sindicato já estivesse em fase mais adiantada de compreensão de suas finalidades, enquanto a emprêsa verificasse a habilitação profissional de seus colaboradores e dos candidatos aos seus quadros, o sindicato de empregados estudaria o comportamento da emprêsa. Atualmente, nas raras ocasiões em que isto ocorre, nem sempre está o sindicato bem informado. Compete, porém, à própria emprêsa, em face de seu caráter institucional, adotar 
uma política de "portas abertas", dar-se a conhecer a todos os "públicos", isto é, a todos os grupos que a ela estejam direta ou indiretamente ligados. No tocante ao âmbito ou frente interna de suas relações, procurará conhecer seus colaboradores através de estudos e pesquisas racionalmente programadas. Certas organizações, aliás, com o louvável intuito de fixar uma imagem favorável na mente de seus trabalhadores e na do grande público - e assim conquistar-lhes a imprescindivel boa-vontade - , desenvolvem intensos programas de interêsse geral da sociedade e específico da comunidade em que atuam.

As vantagens decorrentes de um conhecimento científico dos trabalhadores são muitas:

- Em primeiro lugar, podendo medir o potencial de seus auxiliares, a emprêsa dispõe de meio seguro para preencher, com pessoas adequadas, as vagas de que dispuser.

- Em segundo lugar, ajudando seus colaboradores a realizar-se, ęvita frustrações, aumenta a produtividade e consegue realizar, mais fàcilmente, sua finalidade social .

- Finalmente, a sistematização das anotações e a generalização do registro oferecem à emprêsa a vantagens de propiciar o aproveitamento seguro do potencial dos trabalhadores .

\section{DESCRIÇÃO DO METODO}

O método a que estamos aludindo consiste na criação, para cada empregado ou candidato, de um dossiê composto de duas pastas, prontuário e currículo, sendo êste último o objeto dêste trabalho.

A título tão só de notícia, o prontuário é uma pasta cuja capa estampa as costumeiras "solicitações de emprêgo" que, mais apropriadamente, deveriam chamar-se "propostas para prestação de serviços" - e cujo teor convém ser, de preferência, simples e sucinto para facilitar seu preen- 
chimento. Seguem-se, nas faces internas, de um lado, uma sugestão para o roteiro da entrevista preliminar com o candidato e, de outro, espaço para anotações de dados úteis ao cumprimento da legislação social. Utiliza-se a pasca, outrossim, para arquivamento de tôdas as comunicações sôbre o empregado.

O currículo, para análise do qual remetemos o leitor aos exemplos do Anexo, consta, por seu turno, de três seções, a saber: a) fichas de previsão de desempenho; b) revisões de desempenho ou contrôle; e c) registro da rescisão contratual.

A. Fichas de Previsão de Desempenho - A previsão de desempenho efetua-se através de duas entrevistas, tendo a preliminar caráter psicotécnico e sociológico e sendo a outra destinada à avaliação da habilidade profissional. Os resultados de uma e de outra são condensados, respectivamente, nas Fichas 1 e 2 (vide Anexo), tal como explicaremos a seguir.

- Ficha n..$^{\circ}$ : Resultados da Entrevista Preliminar O selecionador deduzirá da entrefala que mantiver com o candidato as respostas aos quesitos desta seção, atendo-se tão-sòmente ao registro objetivo dos resultałos apurados. É ponto pacífico que tanto a aplicação de testes quanto a direção de entrevistas dessa ordem são misteres cuja execução exige, para que seus resultados possam ser considerados válidos, alta especialização técnica, motivo por que ninguém, com seriedade, se arriscaria a confiá-la a profissionais inaptos. A interpretação dessa ficha permite prever, com certas reservas, o futuro comportamento do candidato, em função de suas condições psicodinâmicas, profissionais, sociais e culturais .

- Ficha n. ${ }^{\circ}$ 2: Resultados da Entrevista Profissional Por via de regra, o emitente da requisição de recrutamento tem interêsse direto no provimento do cargo existente em seu setor. Nada mais razoável, portanto, que deseje participar da seleção do homem que haja de vir a compor seu quadro de colaboradores. A êle se reserva, por 
isso, o exame do candidato sob o ponto de vista profissional "stricto sensu". Para tanto estudará sua experiência, aplicar-1he-á testes específicos. Estribando-se nos dados da entrevista preliminar e em suas próprias observações pessoais, dará seu parecer quanto à eventual admissão do candidato, recomendando o treinamento necessário e registrando os resultados de sua entrevista. Também os resultados do exame médico e das respectivas recomendações serão nesta ficha oportunamente registrados .

B. Revisões de Desempenho - Nas revisões de desempenho - que podem ser feitas através de avaliações de mérito cientificamente elaboradas ou por meio de qualquer outra análise, da conduta do empregado - cada emprêsa utiliza métodos e sistemas particulares. O importante é conferir-lhes caráter e tratamento sigilosos, não obstante devam seus resultados ser analisados, pessoalmente, pelo supervisor que as fizer e pelo empregado a que se refiram. Essa dupla análise permite o acêrto de pequenas incompreensões e não raro possibilita que ambos, supervisor e supervisionado, revejam suas condutas. As revisões, por serem periódicas e de quantidade imprevisível, são registradas em fôlhas sôltas; estas, todavia, devem ser arquivadas como parte integrante do currículo. Abstemo-nos de apresentar modelos, porquanto, como já dissemos, os métodos variam de acôrdo com as atividades de cada emprêsa.

C. Registro da Rescisão Contratual - Na última parte do currículo (vide o Anexo, Ficha n..$^{\circ}$ ) anotam-se os dados referentes à rescisão do contrato individual de trabalho. Nela deverão ser consignados os comentários feitos pelo empregado demitente ou dispensado, bem como as impressões que dêle tenha formado seu supervisor e, ainda, as despesas causadas pela rescisão. Ao final, classifica-se o desligamento, ùnicamente para fins estatísticos . A análise desta parte do currículo dá ensejo a ilações de grande valia para a emprêsa: indicam possíveis desvios dos caminhos preestabelecidos para a implantação de uma sadia política empregatícia; dão margem à correção de 
sérias injustiças cometidas por chefias menos avisadas ou mal preparadas; sugerem aperfeiçoamento de supervisores; auxiliam a racionalização do quadro de pessoal dos diversos departamentos da emprêsa; e, muitas vêzes, corrigem conclusões das entrevistas preliminares.

\section{CONSIDERAÇÕES FINAIS}

A quem procurar introduzir em sua emprêsa um sistema de tratamento de pessoal estruturado com base nos recursos das ciências sociais não deverá causar espécie a resistência que porventura venha a encontrar a princípio. Trata-se de reação normal às inovações que contrariam rotinas consagradas através do tempo. Valerá a pena tentar vencer os obstáculos opostos, máxime quando fôr possivel demonstrar que os resultados hão de ser compensadores, invocando-se a atenção do administrador para aspectos até então subestimados, face à convergência de tôdas as preocupações às áreas de natureza estritamente financeira.

Quase sempre, para que um trabalho dessa ordem possa ser iniciado e desenvolvido com segurança, tornam-se indispensáveis algumas providências preliminares:

- estabelecimento de uma política de pessoal bem definida;

- elaboração de um plano geral de organização bem estruturado;

- instituição de um sistema de descrição e classificação de cargos e funções;

- adoção de processos adequados de contrôle de quantiđade e qualidade da mão-de-obra.

As conseqüências poderão ser, entre outras, o aperfeiçoamento dos métodos de seleção e treinamento, nos diversos níveis hierárquicos, com o aproveitamento adequado, em altas funções, dos elementos que tiverem revelado bom potencial. Finalmente, se a implantação do sistema fôr seguida, paralelamente, de cuidados e atenções especiais no trato com o pessoal, manter-se-á elevado o moral dos empregados. 


\section{ANEXO \\ FICHA N:- 1 \\ PREVISÃO DE DESEMPENHO - A - RESUITADOS DA ENTREVISTA PRELIMINAR}

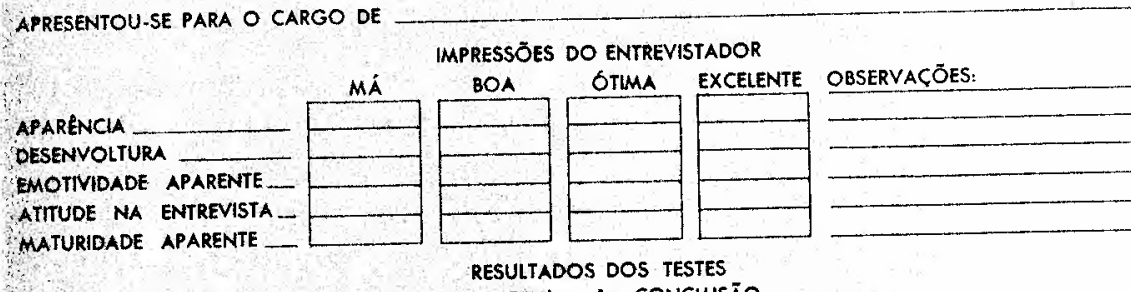

TESTE DE CONHECIMENTO: (NOTA OE ZERO A CEM) TESTE DE RORSCHACH: TESTE DE HABIUDADE:

OUTRO:

OUTRO:

RECOMENDAÇÓES QUANTO AO TREINAMENTO:

SINTESE DA VIDA PROFISSIONAL

CONSTANCLA:

PROGRESSOS:

FRACASSOS:

ASPIRAÇŌES:

REFERENCIAS QUE FEZ AO ÚLTMO EMPRÉGO:

I REFERÉNCIAS QUE FEZZ AO ÚLTIMO CHEFE:

\$TUACÃO DOS SEUS DOCUMENTOS:

CONSEQUUNCIAS FISICAS E JURIDICAS DE ACIDENTE DE TRABALHO:

CAUSA(S) MANTIDA(S) NA JUSTIÇA DO TRABALHO:

OBSERVAÇŌES ESPECIAIS:

RECOMENDÁVEL PARA AS FUNÇȬS DE:

INTREVISTA EM:

SÃO PAULO, DE DE 196 
FICHA N.' 2:

PREVISÃO DE DESEMPENHO - B RESULTADOS DA ENTREVISTA PROFISSIONAL

DISPOSIÇÃO APARENTE INICIATIVA APARENTE POSSIBLLDADE DE ADAPTAÇÃO POSSIBILLADES PROFISSIONAIS
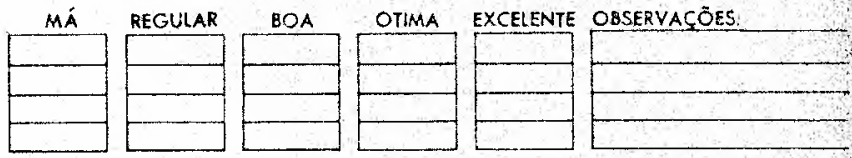

CONHECIMENTOS SÔBRE AS FUNÇÕES QUE EXECUTARÁ:

OBSERVAÇÕEs SÖBRE A EXPERIÊNCIA PROFISSIONAL;

A) QUANTO AS TAREFAS PRÓPRIAS DO CARGO PLEITEADO:

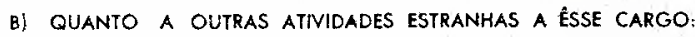

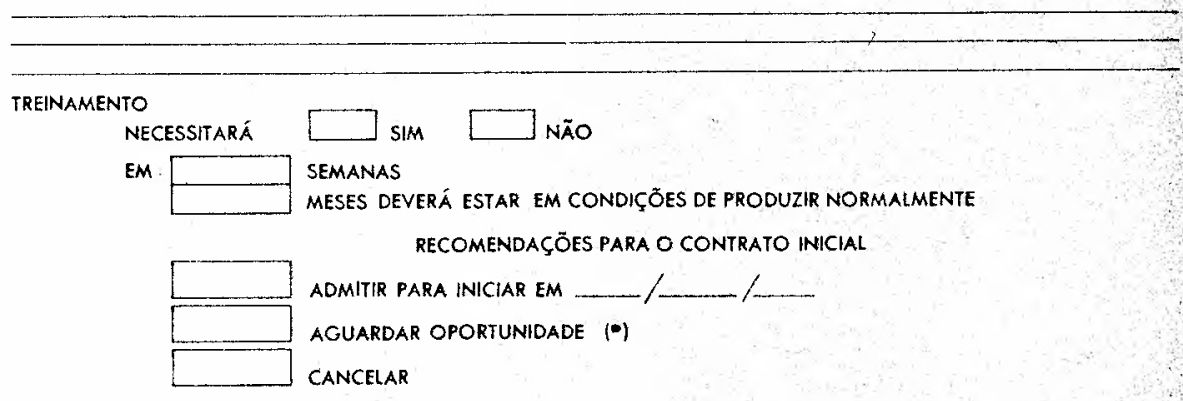

- $)$ Motivos.

ESTABELECER PRAZO EXPERIMENTAL DE DIAS.

SÄO PAULOO, —DE D D D D D D 196 ASSINATURA DO CHEFE REQUISITANTE

EXAME MÉDICO EM: _.__ RESULTADO IFICHA EM PODER DO SERVIÇO MÉOICOI RECOMENDAÇŌES MÉDICAS: 
FICHA N: 3:

\section{REGISTRO DA RESCISÃO CONTRATUAL}

DATA DA RESCISÃO:

SALÁRIO: Cr\$ CARGO SECAAOO

ANOTAÇÕES DEDUZIDAS DA ENTREVISTA NA RESCISÃO MOTIVO DO DESUIGAMENTO, SEGUNDO O EMPREGADO:

COMENTÁRIO SÓBRE A CHEFIA:

SUGESTÕES QUE APRESENTOU E O TRATAMENTO QUE TIVERAM:

SUGESTÕES APRESENTADAS AO SAIR:

ANOTAÇÕES DAS INFORMAÇÕES DADAS PEIO SUPERIOR IMEDIATO MOTIVO DO DESLIGAMENTO, SEGUNDO A CHEFIA:

SÄO PAULO DE DE 196

ENTREVISTADOR

\section{ANOTAÇÕES DO DEPARTAMENTO DO PESSOAL}

TEMPO DE SERVIÇO

ACIDENTES DO TRABALHO:

FREQÜÉNCIA: OUTROS: DISCIPLINA:

\section{CUSIO DA DEMISSÃO}

AVISO PRÉVIO INDENIZACÃO FÉR|AS

13. SALARIO

ACÔRDO

OUTROS

TOTAL

$$
\begin{aligned}
& \mathrm{Cr} \$ \\
& \mathrm{Cr} \$ \\
& \mathrm{Cr} \$ \\
& \mathrm{Cr} \$ \\
& \mathrm{Cr} \$ \\
& \mathrm{Cr} \$ \\
& \mathrm{Cr} \$
\end{aligned}
$$

Indicar no quadrilátero em vermelho o $n{ }^{*}$ correspendente.
CLASSIFICAÇÃO DA RESCISÃO

1.. DEMISSÃO (por vontade do empregodo) 2. DISPENSA SEM JUSTA CAUSA

3.- DISPENSA COM JUSTA CAUSA, SEM RECLAMAÇão 4. D!SPENSA COM JUSTA CAUSA, RECLAMADA 5. ACÔRDO

6. ABANDONO DE EMPRÊGO

7.' MORTE

TAXA DE HOMOLOGAÇÃO.Cr\$ TÊRM:O N. ORGĀO 